Pure Appl. Chem., Vol. 75, No. 1, pp. 19-28, 2003.

(C) 2003 IUPAC

\title{
Synthesis of azaheterocycles from oxime derivatives*
}

\author{
Koichi Narasaka \\ Department of Chemistry, Graduate School of Science, The University of Tokyo, \\ Hongo, Bunkyo-ku, Tokyo 113-0033, Japan
}

Abstract: Electrophilic amination of Grignard reagents has been accomplished by using $O$-sulfonyloximes as amination reagents. Benzophenone $O$-sulfonyloxime derivatives react with Grignard reagents on $\mathrm{sp}^{2}$ nitrogen, yielding primary amines by successive hydrolysis of the resulting $N$-alkylimines.

Various cyclic imines are synthesized by Pd-catalyzed reaction from olefinic oxime derivatives. That is, treatment of $O$-pentafluorobenzoyloximes of olefinic ketones with a catalytic amount of $\mathrm{Pd}\left(\mathrm{PPh}_{3}\right)_{4}$ and triethylamine affords nitrogen-containing heterocycles, such as pyrroles, pyridines, isoquinolines, spiro-imines, and aza-azulenes. This reaction proceeds via the initial formation of alkylideneaminopalladium(II) species generated by oxidative addition of the oximes to the $\operatorname{Pd}(0)$ complex, and the following intramolecular amination on the olefinic moiety.

Cyclic imines are prepared from $\gamma, \delta$-unsaturated $O$-acetyloximes by treatment with acetic acid and 1,4-cyclohexadiene in the presence of a catalytic amount of 1,5-naphthalenediol. $\gamma, \delta$-Unsaturated ketone $O$-methoxycarbonyloximes are transformed to 2-bromomethyl3,4-dihydro- $2 \mathrm{H}$-pyrroles by the action of a catalytic amount of $\mathrm{Cu}(\mathrm{I})$ bromide dimethyl sulfide complex and lithium bromide.

\section{INTRODUCTION}

During the course of study on the catalytic Beckmann rearrangement of oximes by the use of tetrabutylammonium perrhenate and trifluoromethanesulfonic acid [1], we found that $\mathrm{S}_{\mathrm{N}}$ 2-type substitution proceeded on the nitrogen atom of phenethyl ketone oximes in a nonpolar solvent instead of the Beckmann reaction (eq. 1) [2]. In addition, $\mathrm{S}_{\mathrm{N}}$ 2-type cyclization was observed in the reaction of $O$-sulfonyloxime having an active methine group at $\gamma$ - or $\delta$-position with DBU as shown in the following equation [3]. This reaction proceeded in a stereospecific manner: The anti oximes cyclized to five- and six-membered cyclic imines (eq. 2), while the syn isomers did not give any such cyclization products [4].

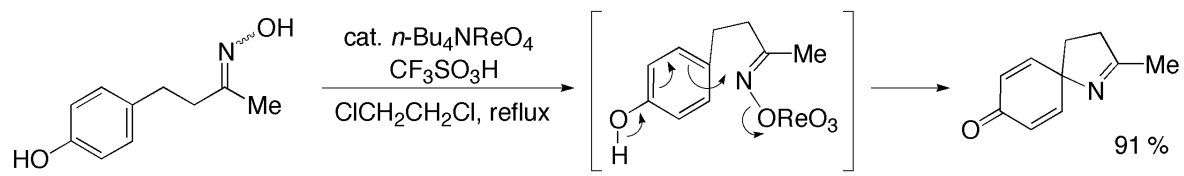

\footnotetext{
*Lecture presented at the $14^{\text {th }}$ International Conference on Organic Synthesis (ICOS-14), Christchurch, New Zealand, 14-18 July 2002. Other presentations are published in this issue, pp. 1-70.
} 


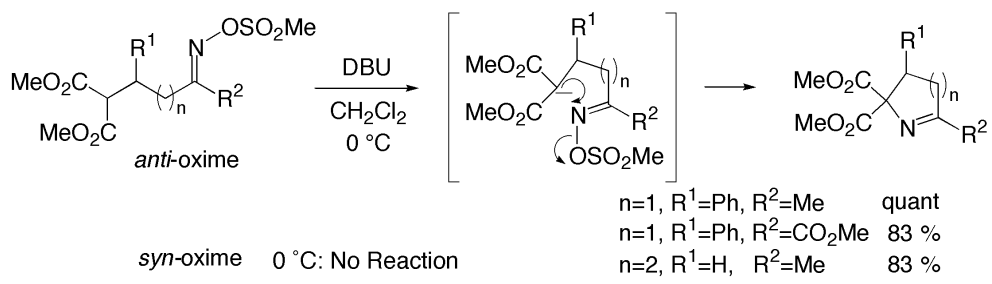

On the contrary, it was found that both of the syn and anti isomers cyclized into cyclic imines when $\gamma, \delta$-unsaturated ketone $O$-2,4-dinitrophenyloximes were treated with reducing agents in the presence of radical trapping reagents [5]. The reaction proceeded via one-electron reduction of $O$-2,4-dinitrophenyloximes with sodium hydride and 3,4-methylenedioxyphenol, followed by radical cyclization with eliminating 2,4-dinitrophenoxide (Scheme 1).

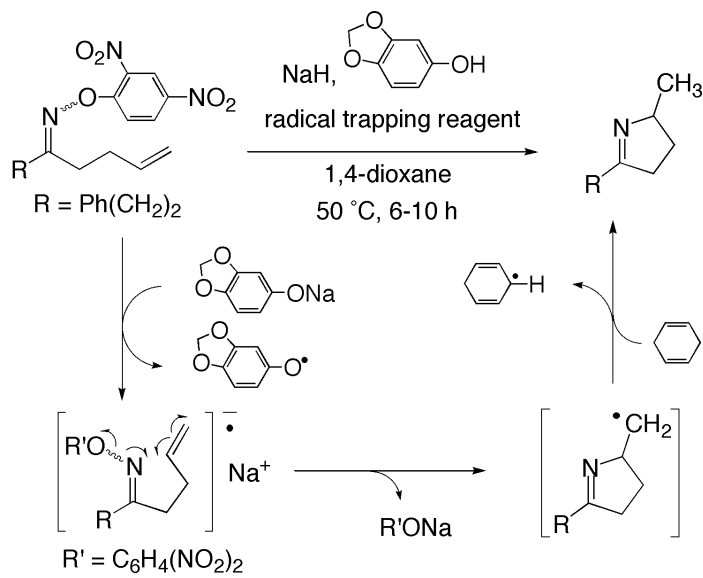

Scheme 1 One-electron reduction of $O$-2,4-dinitrophenyloxime.

These results imply that oxime derivatives could be utilized for amination reagents. However, the above procedures have some drawbacks as synthetic methods. Due to the stereospecificity of the $\mathrm{S}_{\mathrm{N}}$ 2-type cyclization, only the anti isomer can be employed for the intramolecular reaction. In the electron-transfer reaction, it is needed to use large excess amounts of sodium hydride and to introduce a bulky leaving group such as 2,4-dinitrophenoxy group. Hence, we have been studying the improvement of the above carbon-nitrogen bond-forming reactions for the synthesis of nitrogen-containing compounds. The following points should be realized to use oxime derivatives for amination reactions: (1) suppressing the Beckmann reaction, (2) overcoming syn/anti stereospecificity of the $\mathrm{S}_{\mathrm{N}}$ 2-type reaction, (3) use of simple oxime derivatives, and (4) designing catalytic process.

\section{PREPARATION OF PRIMARY AMINES FROM O-SULFONYLOXIMES AND GRIGNARD REAGENTS}

In general, primary amines are prepared by the reduction of the compounds bearing a nitrogen function such as nitro and azide groups or the Gabriel-type nucleophilic amination reactions. Although electrophilic amination is another method to prepare primary amines, it has been rarely employed in organic synthesis [6]. As mentioned in the above $\mathrm{S}_{\mathrm{N}}$ 2-type reaction, oxime derivatives were found to behave as electrophilic amination reagents. On the basis of the findings, the reaction of oxime derivatives and organometallic reagents was examined. There have been reported reactions of this type. Hagopian prepared primary arylamines by the reaction of tetraphenylcyclopentadienone $O$-sulfonyloxime with large 
excess amounts of arylmagnesium and lithium compounds, whereas dialkylation occurred with alkylmetals [7]. Erik reported the reaction of acetone $O$-sulfonyloxime with Grignard reagents, which gave primary amines in moderate-to-low yield [8].

For amination reagents, we chose 4,4'-bis(trifluoromethyl)benzophenone $O$-methylsulfonyloxime (1) and 3,3',5,5'-tetrakis(trifluoromethyl)benzophenone $O$-p-tolylsulfonyloxime (2), which have no acidic hydrogen at $\alpha$ position and have electron-withdrawing groups on the phenyl group to suppress the Beckmann rearrangement [9]. Although bis(trifluoromethyl) $O$-sulfonyloxime $\mathbf{1}$ reacted with alkyl Grignard reagents in low yield, $\mathrm{CuCN} \cdot 2 \mathrm{LiCl}$ catalyzed the amination in a mixed solvent of tetrahydrofuran (THF) and hexamethylphosphoramide (HMPA) (eq. 3). Primary-, secondary-, and tertiary-alkyl primary amines are synthesized in high yields by this $\mathrm{Cu}$-catalyzed electrophilic amination, whereas this method cannot be applied to the preparation of aniline derivatives from aryl Grignard reagents due to the formation of biphenyl derivatives.

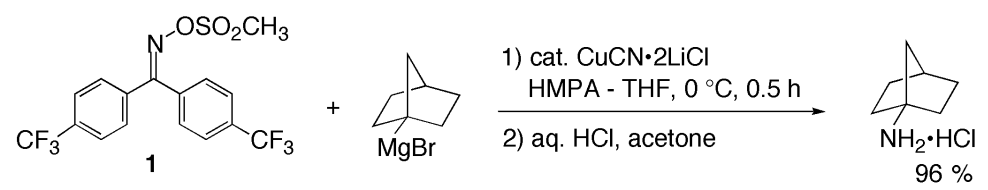

In the absence of the copper catalyst, a marked solvent effect was observed in the reaction of 3,3',5,5'-tetrakis(trifluoromethyl)benzophenone $O$-p-tolylsulfonyloxime 2 and phenyl Grignard reagent. Treatment of $\mathbf{2}$ in toluene with phenylmagnesium bromide generated in THF afforded benzanilide in $15 \%$ yield with the recovery of the starting material 2 (eq. 4). The same reaction with the Grignard reagent prepared in ether provided benzanilide in $96 \%$ yield. Even a sterically hindered Grignard reagent, 2,6-dimethylphenylmagnesium bromide, reacted smoothly with $\mathbf{2}$ to yield 2,6-dimethylanilide in $98 \%$ yield (Table 1). In addition to aniline formation, this method found the application to prepare primary- and secondary-alkyl primary amines, while the amination of tertiaryalkyl Grignard reagent produced a low yield of the product.

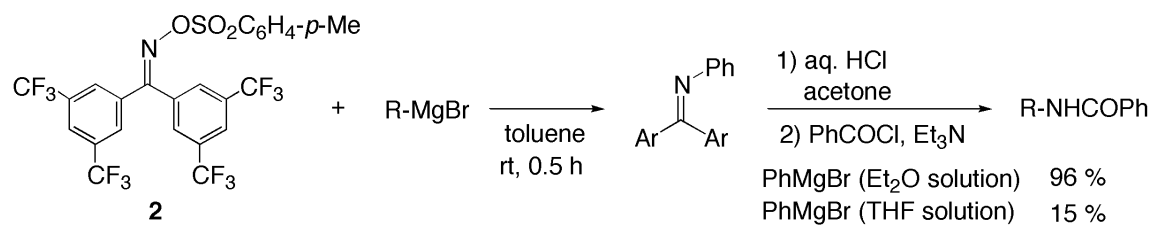

Table 1 Amination of Grignard reagent with benzophenone oxime 2.

\begin{tabular}{lllll}
\hline & Yield/\% & & \\
\hline
\end{tabular}




\section{PREPARATION OF AZAHETEROCYCLES BY Pd-CATALYZED CYCLIZATION OF OLEFINIC OXIMES}

Due to their electron-donor property of lower-valent transition-metal compounds, $\operatorname{Pd}(0)$ complexes were expected to react with oxime derivatives to generate oxidative addition products, alkylideneaminopalladium complexes. In fact, when 4,4'-bis(trifluoromethyl)benzophenone $O$-methylsulfonyloxime (1) was treated with an equimolar amount of $\mathrm{Pd}\left(\mathrm{PPh}_{3}\right)_{4}$, benzophenone imine 4 was isolated quantitatively after hydrolysis (eq. 5).

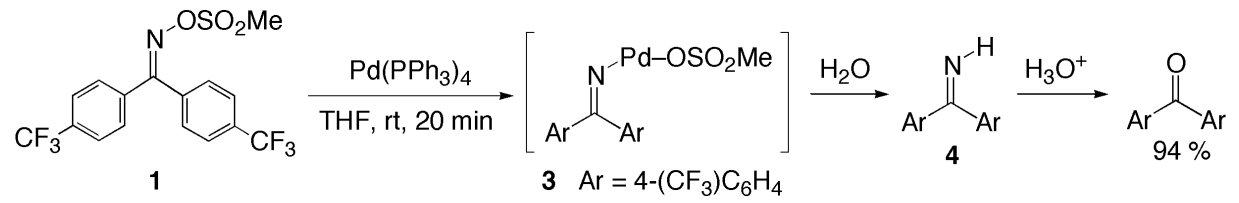

This results suggested that $O$-sulfonyloxime readily underwent oxidative addition to $\operatorname{Pd}(0)$ complex to generate alkylideneaminopalladium(II) species $\mathbf{3}$, which was then hydrolyzed to imine $\mathbf{4}$. Although this oxidative addition species has not been successfully isolated, the generation of such an intermediate may be reliable, because a similar oxidative addition of oxime to $\operatorname{Re}(\mathrm{I})$ complex was reported recently [10]. To utilize this aminopalladium species for organic synthesis, the intramolecular amino-Heck reaction was investigated on $\gamma, \delta$-unsaturated ketone $O$-sulfonyloxime 5a [11]. In fact, 3-methyl-5-phenethylpyrrole (7a), which is an isomerization product of the initially formed 4-methylidene-2-phenethyl-3,4-dihydro-2H-pyrrole (6), was obtained in $66 \%$ yield by a catalytic use of $\mathrm{Pd}(\mathrm{OAc})_{2} / \mathrm{P}(o-\mathrm{Tol})_{3}$ and triethylamine, whereas the Beckmann rearrangement was also observed (eq. 6).

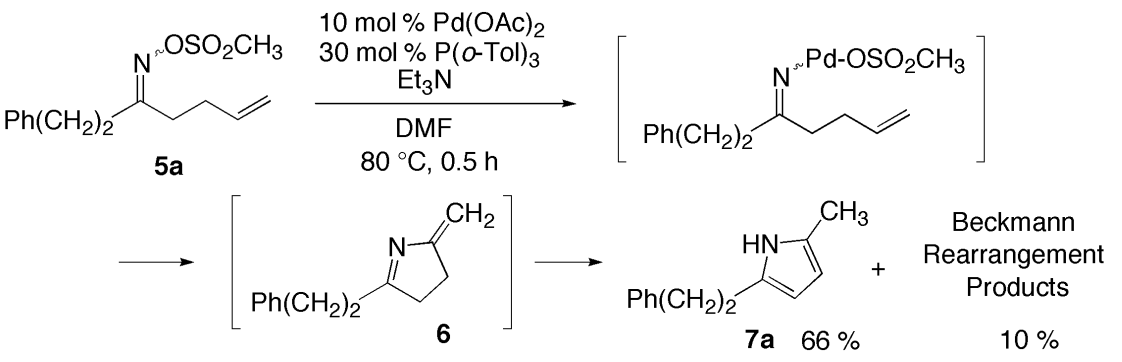

To avoid the rearrangement, $O$-pentafluorobenzoyloxime was found to be suitable for this cyclization reaction. $O$-Pentafluorobenzoyloxime $\mathbf{5 b}$ was converted to pyrrole $\mathbf{7 b}$ in good yield by the aminoHeck cyclization followed by isomerization of the crude products with trimethylsilyl chloride without the Beckmann rearrangement (eq. 7). It is noteworthy that the stereochemistry of the oximes exhibited no significant influence on the cyclization.<smiles>C=CCCc1ccccc1</smiles>

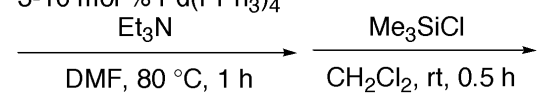

from $E$-isomer from Z-isomer

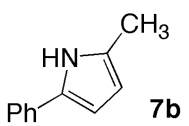

$83-85 \%$ $82 \%$

This amino-Heck reaction can be widely applied to prepare pyrrole derivatives. Various $\gamma, \delta$-unsaturated ketone oximes having terminal methylene group and monosubstituted methylene group cyclized to pyrroles smoothly (eqs. 8 and 9). 
<smiles>C=CCC1CCc2ccccc2/C1=N/OC(=O)OC(F)(F)F</smiles>

1) $10 \mathrm{~mol} \% \mathrm{Pd}\left(\mathrm{PPh}_{3}\right)_{4}$ $\mathrm{Et}_{3} \mathrm{~N}$ 2) $\mathrm{Me}_{3} \mathrm{SiCl}$ $\mathrm{CH}_{2} \mathrm{Cl}_{2}$, rt, $0.5 \mathrm{~h}$<smiles>Cc1cc2c([nH]1)-c1ccccc1CC2</smiles><smiles>[R3]C=CC(CC([R])=O)C/C([R7])=N\OC(=O)OC(F)(F)F</smiles>

1) $10 \mathrm{~mol} \% \mathrm{Pd}\left(\mathrm{PPh}_{3}\right)_{4}$ $\mathrm{Et}_{3} \mathrm{~N}$ $\mathrm{DMF}, 80^{\circ} \mathrm{C}, 1 \mathrm{~h}$ 2) $\mathrm{Me}_{3} \mathrm{SiCl}$ $\mathrm{CH}_{2} \mathrm{Cl}_{2}, \mathrm{rt}, 0.5 \mathrm{~h}$<smiles>[R3]Cc1[nH]c([R])cc1[R]</smiles>

$\mathrm{R}^{1}=\mathrm{Ph}, \mathrm{R}^{2}=\mathrm{CH}_{3}, \mathrm{R}^{3}=\mathrm{H} \quad 80 \%$ $\mathrm{R}^{1}=\mathrm{CO}_{2} \mathrm{Me}, \mathrm{R}^{2}=\mathrm{H}, \mathrm{R}^{3}=\mathrm{CO}_{2} \mathrm{Et} \quad 78 \%$

Thus, the 5-exo mode cyclization proceeds in $\gamma, \delta$-unsaturated ketone $O$-pentafluorobenzoyloximes via alkylideneaminopalladium species, while the 6-endo mode of cyclization was observed in the reaction of $\gamma, \delta$-unsaturated ketone oximes 8 having $\beta$-methoxy group. Particularly in the presence of tetrabutylammonium chloride, pyridine derivatives $\mathbf{9}$ were obtained in reasonable yields (eq. 10) [12]. The reaction pathway of this 6-endo mode cyclization has been not clear, but the reaction is certainly initiated by the oxidative addition of the oximes.

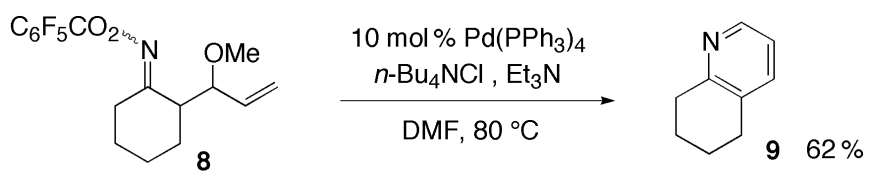

Under these reaction conditions, ortho-allylphenyl ketone $O$-pentafluorobenzoyloxime $\mathbf{1 0}$ also cyclized to give various isoquinoline derivatives in the mode of 6-exo mode cyclization (eq. 11).

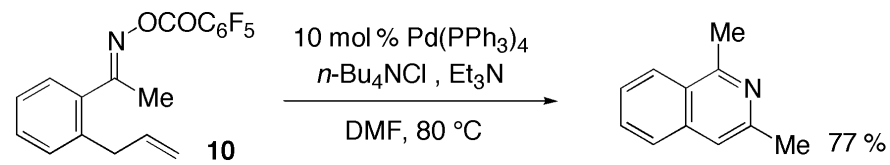

Various methods have been developed towards the construction of 1-azaspiro[4.4]nonane skeleton, including a recent metal-catalyzed allylation reaction [13]. This amino-Heck reaction provides another metal-catalyzed method for the synthesis of 1-azaspiro[4.4]nonane derivatives. Bicyclic and tricyclic imines could be prepared in domino cyclization from dienyl and trienyl ketone oximes (eq. 12).<smiles>C=CCCC(=C)CCC(CCc1ccccc1)=NOC(=O)OC(F)(F)F</smiles>
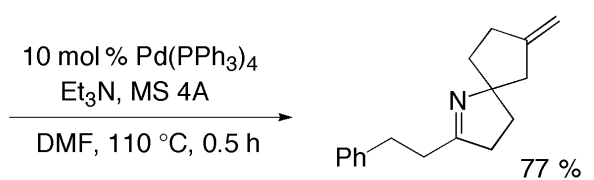<smiles>C=C1CCC2(C1)CC1CCc3ccccc3C1=N2</smiles>

$80 \%(1: 1)$

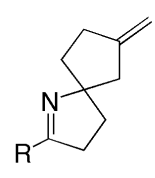

$\mathrm{R}=\mathrm{Ph} \quad 82 \%$ $\mathrm{R}=\mathrm{CO}_{2} \mathrm{Et} 76 \%$

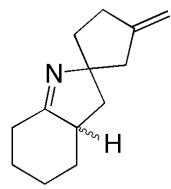

$64 \%(1: 1)$<smiles>C=C1CCC2(CCC3(CCC(c4ccccc4)=N3)C2)C1</smiles>

$77 \%(4: 3)$ 
A straightforward method is developed for the synthesis of aza-azulenes. 1-Aza-azulenes $\mathbf{1 3}$ were obtained by treatment of cycloheptatrienylmethyl ketone $O$-pentafluorobenzoyloximes 12 with $\mathrm{Pd}(\mathrm{dba})_{2} / \mathrm{P}(t-\mathrm{Bu})_{3}$ and triethylamine and the successive oxidation of the crude mixture with $\mathrm{MnO}_{2}$ (eq. 13, Table 2) [14].

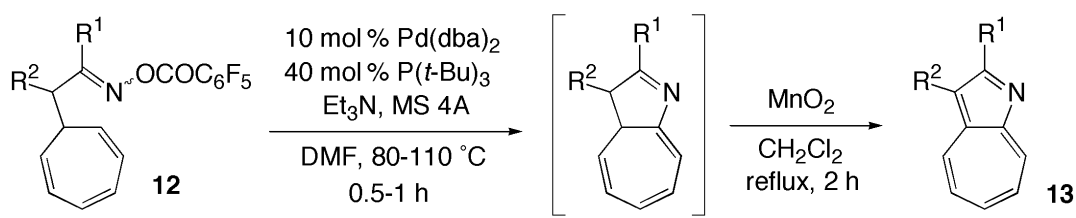

Table 2 Preparation of 1-aza-azulenes 13.

\begin{tabular}{|c|c|c|c|c|c|}
\hline $\mathrm{R}^{1}$ & $\mathrm{R}^{2}$ & Yield/\% & $\mathrm{R}^{1}$ & $\mathrm{R}^{2}$ & Yield $/ \%$ \\
\hline $\mathrm{Ph}$ & $\mathrm{H}$ & 78 & $\mathrm{Ph}$ & $\mathrm{Me}$ & 52 \\
\hline$t-\mathrm{Bu}$ & $\mathrm{H}$ & 84 & $\mathrm{Ph}$ & $\mathrm{Ph}$ & 84 \\
\hline$i-\operatorname{Pr}$ & $\mathrm{H}$ & 62 & Et & $\mathrm{Me}$ & 42 \\
\hline & $\mathrm{H}$ & 63 & $=\mathrm{Ph}$ & $\mathrm{H}$ & $0^{*}$ \\
\hline 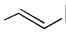 & $\mathrm{H}$ & 68 & & & \\
\hline $\mathrm{Me}$ & $\mathrm{H}$ & 27 & & & \\
\hline
\end{tabular}

\section{CYCLIZATION OF $\gamma, \delta$-UNSATURATED KETONE O-ACYLOXIMES}

Although oximes themselves readily isomerize by treatment with acid, isomerization of $O$-substituted oximes hardly occurs under acidic conditions. This makes the application of $\mathrm{S}_{\mathrm{N}} 2$-type cyclization to cyclic imine preparation difficult, because it is hard to synthesize $E$ or $Z$ oximes in a stereoselective manner. In order to apply the $\mathrm{S}_{\mathrm{N}}$ 2-type substitution, therefore, we have investigated some isomerization of $O$-substituted oximes under mild conditions.

When $O$-chlorodifluoroacetyloxime was treated with trifluoroacetic acid at room temperature (rt), formation of $O$-trifluoroacetyloxime was observed and the reaction came up to be in equilibrium after $22 \mathrm{~h}$ (eq. 14). Thus, $O$-acyloximes have the possibility of syn/ant $i$ isomerization, presumably due to the formation of free oximes as intermediates.

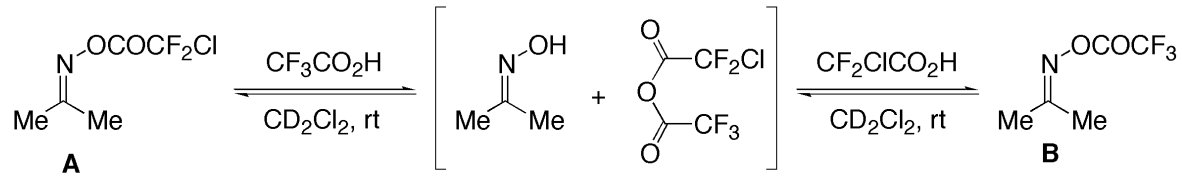

Syn/anti isomerization of a 1:1 mixture of $E$ and $\mathrm{Z} O$-methyloximes did not occur with a nonnucleophilic acid such as trifluoromethanesulfonic acid, while $O$-methyloximes isomerized by treatment with acetic acid at $80^{\circ} \mathrm{C}$, although the isomerization proceeded very slowly (eq. 15). The isomerization was found to be accelerated by the addition of a catalytic amount of phenol derivatives like 1,4-hydroquinone and 1,5-naphthalenediol. After $2 \mathrm{~h}$ at $80^{\circ} \mathrm{C}$, the syn/anti isomers attained to the equilibrium.

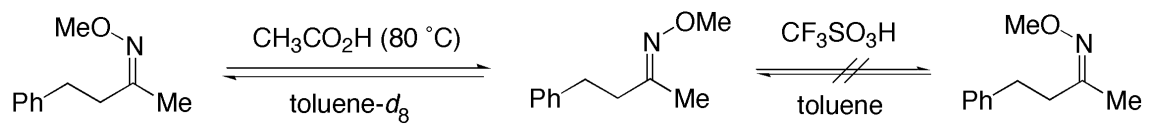


Cyclization of $\gamma, \delta$-unsaturated $O$-acetyloxime 14a was tried by treatment with 2 molar amounts of acetic acid and a catalytic amount of 1,5-naphthalenediol in refluxing 1,4-dioxane (eq. 16, Table 3) [15]. The desired cyclization product 15a was obtained in about $23 \%$ yield, with $43 \%$ yield of unexpected 2-methyl-5-phenethyl-3,4-dihydro-2H-pyrrole (16a) (Run 1). When the reaction was carried out in the presence of 1,4-cyclohexadiene, the total yield of 15a and 16a increased to $86 \%$ (Run 3). Without the naphthalenediol, the reaction proceeded very slowly, and the total yield was low (Runs 2 and 4).

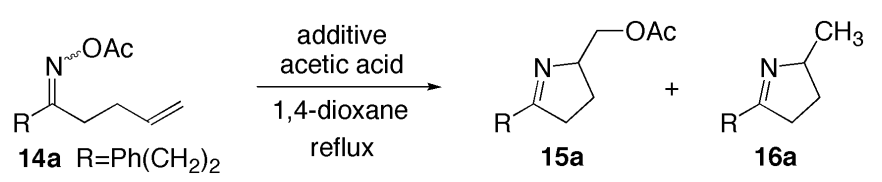

Table 3 Cyclization of $O$-acetyloxime $\mathbf{1 4 a}$.

\begin{tabular}{lllrrr}
\hline Run & \multicolumn{1}{c}{$\begin{array}{c}\text { Additive } 1 \\
(5 \mathrm{~mol} \%)\end{array}$} & \multicolumn{1}{c}{$\begin{array}{c}\text { Additive } 2 \\
(1000 \mathrm{~mol} \%)\end{array}$} & Time & \multicolumn{2}{c}{ Yield/\% } \\
\cline { 5 - 6 } & \multicolumn{1}{c}{ 1,5-naphthalenediol } & none & $6 \mathrm{~h}$ & 23 & $\mathbf{1 6 a}$ \\
2 & none & none & $24 \mathrm{~h}$ & 19 & 20 \\
3 & 1,5-naphthalenediol & 1,4-cyclohexadiene & $6 \mathrm{~h}$ & 34 & 52 \\
4 & none & 1,4-cyclohexadiene & $24 \mathrm{~h}$ & 12 & 29 \\
\hline
\end{tabular}

The formation of the unexpected product 16a could not be explained by the $\mathrm{S}_{\mathrm{N}}$ 2-type mechanism, but was considered to stem from a radical process [16]. Actually, by the reaction in toluene- $d_{8}$ without 1,4-cyclohexadiene, the cyclic imine 16a was obtained in $17 \%$ yield with $65 \%$ deuterium content in the methyl group along with $26 \%$ yield of 15a (eq. 17).

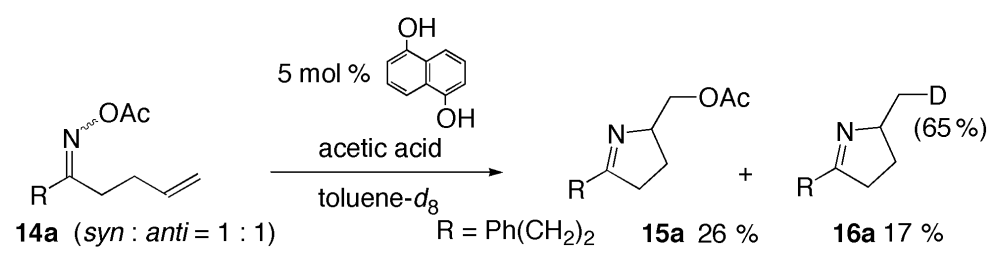

By the reaction of $O$-acetyloxime 14b having an electron-rich olefinic moiety, acetoxymethyl imine $\mathbf{1 5 b}$ was yielded as a major product. In contrast, only radical cyclization products $\mathbf{1 6 c}$ and $\mathbf{1 6 d}$ were obtained from oximes having electron-deficient olefinic moieties. Radical cyclization product 16e was obtained exclusively from $O$-acetyloxime of phenyl ketone. Presumably, the steric repulsion between phenyl and acetoxy group gives rise to the preferential formation of the syn isomer, which prevents the nucleophilic substitution with the intramolecular alkenyl group. $O$-Pivaloyloxime of $\alpha$-keto ester also gave only methylimino ester $\mathbf{1 6 f}$ in $61 \%$ yield (eq. 18, Table 4).

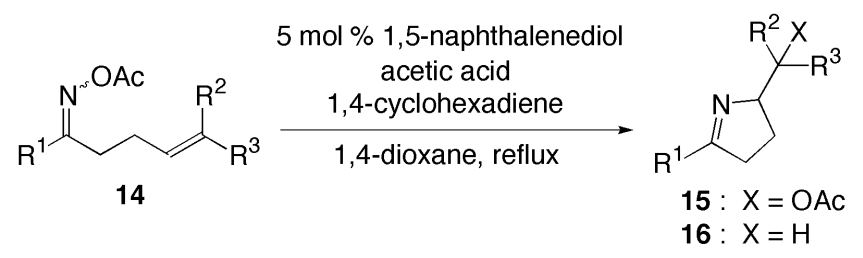


Table 4 Cyclization of $O$-acetyloxime $14^{\mathrm{a}}$.

\begin{tabular}{|c|c|c|c|c|c|c|c|}
\hline Run & $\mathrm{R}^{1}$ & $\mathrm{R}^{2}$ & $\mathrm{R}^{3}$ & Time/h & & Yiel & \\
\hline 1 & $\mathrm{PhCH}_{2} \mathrm{Ch}_{2}{ }^{\mathrm{b}}$ & $\mathrm{H}$ & $\mathrm{H}$ & 6 & $15 \mathbf{a}$ & 34 & $16 \mathbf{a} 52$ \\
\hline 2 & $\mathrm{PhCH}_{2} \mathrm{Ch}_{2}{ }^{\mathrm{b}}$ & $\mathrm{Me}$ & $\mathrm{Me}$ & 6 & $15 b$ & 72 & 16b 5 \\
\hline 3 & $\mathrm{PhCH}_{2} \mathrm{Ch}_{2}{ }^{\mathrm{c}}$ & $\mathrm{H}$ & $\mathrm{CN}$ & 12 & $15 c$ & 0 & 16c 69 \\
\hline 4 & $\mathrm{PhCH}_{2} \mathrm{Ch}_{2}{ }^{\mathrm{b}}$ & $\mathrm{H}$ & $\mathrm{CO}_{2} \mathrm{Et}$ & 12 & $15 d$ & 0 & 16d 72 \\
\hline 5 & $\mathrm{Ph}^{\mathrm{d}} \quad 2$ & $\mathrm{H}$ & $\mathrm{H}^{2}$ & 8 & $15 e$ & 0 & 16e 75 \\
\hline 6 & $\mathrm{Ph}\left(\mathrm{CH}_{2}\right)_{3} \mathrm{O}_{2} \mathrm{C}^{\mathrm{d}, \mathrm{e}}$ & $\mathrm{H}$ & $\mathrm{H}$ & 6 & $15 f$ & 0 & 16f 61 \\
\hline
\end{tabular}

As mentioned in the introductory section, one-electron reduction activates $O$-2,4-dinitrophenyloxime derivatives to react with intramolecular phenyl and alkenyl moieties via a radical process. It was expected that one-electron reduction of oxime derivatives would proceed by the action of low-valent transition-metal compounds. Such an example was reported by Zard. That is, the treatment of $\gamma, \delta$-unsaturated $O$-acetyloximes with nickel powder and acetic acid in 2-propanol leads to the cyclization to dihydropyrroles [17]. This reaction, however, requires large excess amounts of nickel powder, and it is desirable to conduct such a transformation in a catalytic manner.

By using copper compounds as metal catalysts [18], we examined the cyclization of various $\gamma, \delta$-unsaturated oximes. After screening, the substituents on the oxime nitrogen atom (vide infra), $O$-methoxycarbonyloximes were found to be suitable for the transformation of $\gamma, \delta$-unsaturated oximes to dihydropyrroles. The reaction of a syn/anti (1:1) mixture of $O$-methoxycarbonyloxime 17 with $5 \mathrm{~mol} \%$ of $\mathrm{CuBr} \cdot \mathrm{SMe}_{2}$ in 1,4-dioxane $80{ }^{\circ} \mathrm{C}$, cyclic imine 18a was obtained in $39 \%$ yield (eq. 19 , Table 5, Run 1). Thus, the reaction proceeded catalytically, though the yield was not good. The yield was much improved to $86 \%$ by the addition of $\operatorname{LiBr}$ (Run 4 ).

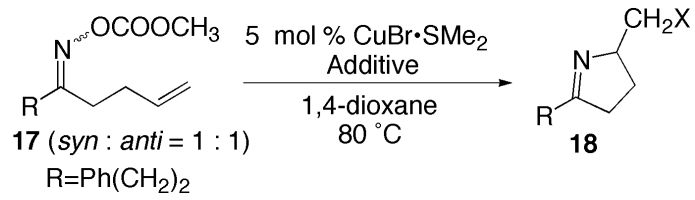

Table $5 \mathrm{Cu}$-catalyzed cyclization of $1 \mathbf{7}^{\mathrm{a}}$.

\begin{tabular}{clcll}
\hline Run & Additive & Time & $\mathrm{X}$ & \multicolumn{1}{c}{ Yield/\% } \\
\hline 1 & none & $1 \mathrm{~h}$ & $\mathrm{H}$ & $\mathbf{1 8 a} 39$ \\
2 & $\left(\mathrm{Me}_{3} \mathrm{Si}\right)_{3} \mathrm{SiH}$ & $1 \mathrm{~h}$ & $\mathrm{H}$ & $\mathbf{1 8 a} 49$ \\
3 & $\mathrm{PhSSPh}$ & $3 \mathrm{~h}$ & $\mathrm{SPh}$ & $\mathbf{1 8 b} 41^{\mathrm{b}}$ \\
4 & $\mathrm{LiBr}$ & $1 \mathrm{~h}$ & $\mathrm{Br}$ & $\mathbf{1 8 c} 86$ \\
5 & $\mathrm{LiCl}^{\mathrm{c}}$ & $1 \mathrm{~h}$ & $\mathrm{Cl}$ & $\mathbf{1 8 d} 57^{\mathrm{d}}$ \\
\hline
\end{tabular}

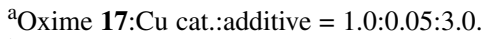

${ }^{\mathrm{b}} \mathbf{1 8 a}$ was obtained in $14 \%$ yield.

${ }^{\mathrm{c}} \mathrm{CuCl}$ was used instead of $\mathrm{CuBr} \cdot \mathrm{Sme}_{2}$.

e 18 a was obtained in $18 \%$ yield. 
In addition to $O$-methoxycarbonyloxime 17, $O$-pentafluorobenzoyloxime 19 was transformed into $18 \mathrm{c}$ in high yield, but the corresponding $O-2,4$-dinitrophenyl and $O$-acetyloxime were not appropriate for the $\mathrm{CuBr} \cdot \mathrm{LiBr}$-catalyzed cyclization. The cyclization proceeds irrespective of the stereochemistry of $O$-pentafluorobenzoyloxime 19. The cyclization product $18 \mathrm{c}$ was obtained in $86 \%$ and $91 \%$ yield from the syn and anti isomers 19, respectively (eq. 20).

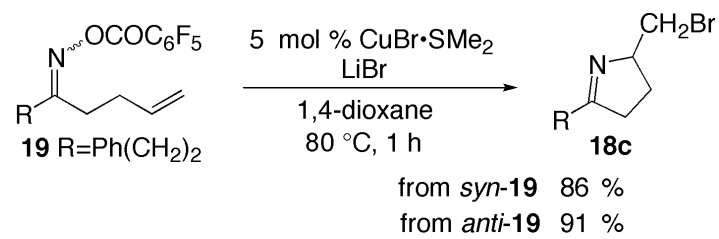

As listed in Table 6, the catalytic system of $\mathrm{CuBr} \cdot \mathrm{SMe}_{2} \cdot \mathrm{LiBr}$ was applied to the cyclization of various $\gamma, \delta$-unsaturated ketone $O$-methoxycarbonyloximes. Cyclization of 20a and 20b having disubstituted olefin moiety proceeded to give cyclic imines $\mathbf{2 1 a}$ and $\mathbf{2 1 b}$ in $85 \%$ and $74 \%$ yield, respectively (Table 6, Runs 1 and 2). 5,5-Disubstituted dihydropyrrole 21c was obtained in $53 \%$ yield from $\gamma$-methyl substituted oxime 20c along with $16 \%$ yield of disubstituted pyridine 22 (Run 3) [19]. Oxime derivatives of phenyl ketone 20d and keto ester 20e were smoothly transformed into 2-phenyl and 2-ethoxycarbonyl dihydropyrroles 21d and 21e, respectively (Runs 4 and 5).

Table 6 Cu-catalyzed cyclization of $\mathbf{2 0}^{\mathrm{a}}$.

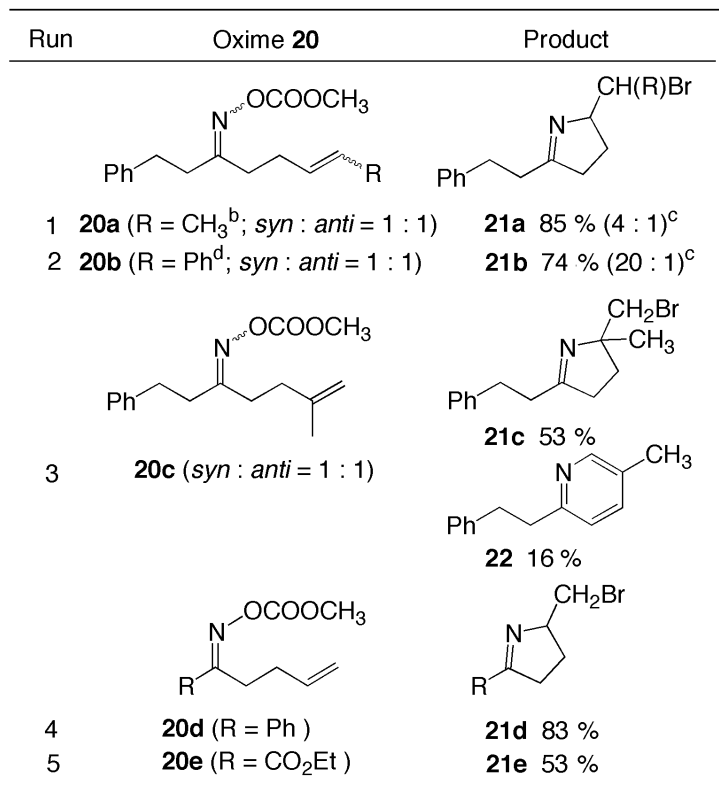

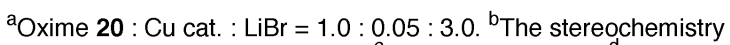

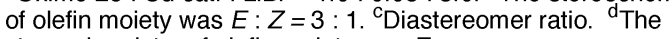
stereochemistry of olefin moiety was $E$.

Very recently, a Cu-catalyzed radical cyclization of unsaturated $\mathrm{N}$-benzoyloxyamines to pyrrolidines was reported [20]. Totally, various dihydropyrrols and pyrrolidines can be prepared by Cu-catalyzed radical cyclization processes. 


\section{REFERENCES}

1. H. Kusama, Y. Yamashita, K. Narasaka. Bull. Chem. Soc. Jpn. 68, 373 (1995).

2. H. Kusama, Y. Yamashita, K. Uchiyama, K. Narasaka. Bull. Chem. Soc. Jpn. 70, 965 (1997).

3. S. Mori, K. Uchiyama, Y. Hayashi, K. Narasaka, E. Nakamura. Chem. Lett. 111 (1998).

4. K. Uchiyama, M. Yoshida, Y. Hayashi, K. Narasaka. Chem. Lett. 607 (1998); M. Yoshida, K. Uchiyama, K. Narasaka. Heterocycles 52, 681 (2000).

5. K. Uchiyama, Y. Hayashi, K. Narasaka. Tetrahedron 55, 8915 (1999).

6. A. Casarini, P. Dembech, D. Lazzari, E. Marini, G. Reginato, A. Ricci, G. Seconi. J. Org. Chem. 58, 5620 (1993); C. Greck and J.-P. Genêt. Synlett 741 (1997); E. Erdik and M. Ay. Chem. Rev. 89, 1947 (1989); "Formation of C-N Bonds by Electrophilic Amination," in Stereoselective Synthesis, G. Helmchen, R. W. Hoffmann, J. Mulzer, E. Schaumann (Eds.), Vol. 7, p. 5113, Georg Thieme, Stuttgart (1997) and references cited therein.

7. R. A. Hagopian, M. J. Therien, J. R. Murdoch. J. Am. Chem. Soc. 106, 5753 (1984).

8. E. Erdik and M. Ay. Synth. React. Inorg. Met.-org. Chem. 19, 663 (1989).

9. H. Tsutsui, Y. Hayashi, K. Narasaka. Chem. Lett. 317 (1997); H. Tsutsui, T. Ichikawa, K. Narasaka. Bull. Chem. Soc. Jpn. 72, 1869 (1999).

10. C. M. P. Ferreira, M. F. C. Guedes da Silva, V. Y. Kukushkin, J. J. R. Fraústo da Silva, A. J. L. Pombeiro. J. Chem. Soc., Dalton Trans. 325 (1998).

11. H. Tsutsui and K. Narasaka. Chem. Lett. 45 (1999).

12. H. Tsutsui and K. Narasaka. Chem. Lett. 526 (2001).

13. M. Kitamura, S. Zaman, K. Narasaka. Synlett 974 (2001).

14. M. Kitamura, S. Chiba, O. Saku, K. Narasaka. Chem. Lett. 606 (2002).

15. M. Yoshida, M. Kitamura, K. Narasaka. Chem. Lett. 144 (2002).

16. A. G. Fallis and I. M. Brinza. Tetrahedron 53, 17543 (1997).

17. J. Boivin, A.-M. Schiano, S. Z. Zard, H. Zhang. Tetrahedron Lett. 40, 4531 (1999).

18. In recent years, there have been some reports on the radical addition of trichloromethyl carbonyl compounds to intramolecular olefin moiety mediated by a catalytic amount of copper complexes of bipyridine ${ }^{18 \mathrm{a}, \mathrm{b}}, N$-alkyl-2-pyridylmetanimine ${ }^{18 \mathrm{c}, \mathrm{d}}$, or multidentate amines ${ }^{18 \mathrm{c}, \mathrm{e}, \mathrm{f}}$ as redox catalysts. (a) H. Nagashima, Y. Isono, S.-i. Iwamatsu. J. Org. Chem. 66, 315 (2001); (b) S.-i. Iwamatsu, H. Kondo, K. Matsubara, H. Nagashima. Tetrahedron 55, 1687 (1999); (c) A. J. Clark, R. P. Filik, G. H. Thomas. Tetrahedron Lett. 40, 4885 (1999); (d) A. J. Clark, R. P. Filik, D. M. Haddleton, A. Radique, C. J. Sanders, G. H. Thomas, M. E. Smith. J. Org. Chem. 64, 8954 (1999); (e) A. J. Clark, F. de Campo, R. J. Deeth, R. P. Filik, S. Gatard, N. A. Hunt, D. Lastécouères, G. H. Thomas, J.-B. Verlhac, H. Wongtap. J. Chem. Soc., Perkin Trans 1 671 (2000); (f) F. de Campo, D. Lastécouères, J.-B.Verlhac. Chem. Commun. 2117 (1998).

19. Probably, pyridine $\mathbf{2 6}$ was formed by 6 -endo cyclization, dehydrogenation, and successive oxidation.

20. M. Noack and R. Göttlich. Chem. Commun. 536 (2002). 